


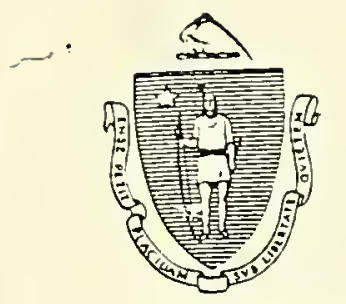

MICHAEL S. DUKAKIS GOVERNOR

JAMES S. HOYTE SECRETARY

\section{The Commonwealth of Massachuselts}

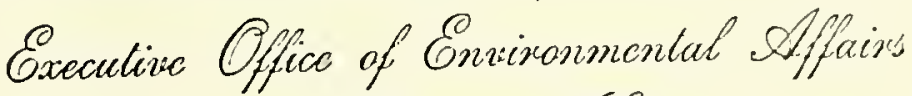

100 Cambridge Sired

Doston, Massactusetlis 02202

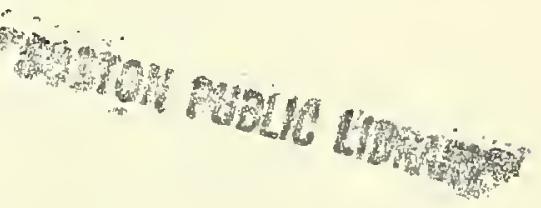

GOVDOC

BRA

4631
CERTIFICATE OF THE SECRETARY OF ENVIRONMENTAL AEFAIRS ON THE
PROJECT NAME

PROJECT LOCATION

EOEA NUMBER

PROJECT PROPONENT DATE NOTICED IN MONITOR : December 24, 1985
: Fan Pier/Pier 4 Developments

: South Boston

: $4426 / 4584$

$\because$ HBC Associates/The Boston Mariner Co

The Secretary of Environmental Affairs herein issues a statement that the Draft Environmental Impact Report submitted the above project adequately and properly complies with the Massachusetts Environmental Policy Act (G.I., c.30, S.62-62H) with its implementing regulations (301 CMR 10.00).

\section{OVERVIEW}

Boston Harbor is the premier natural resource of urban eastern Massachusetts. Historically, it fostered the foundatic of the City, sponsored its growth as a maritime shipping cente supported it as an industrial and fishing center, witnessed th decline of these traditional uses, and, more recently, nosted dramatic rebirth of mixed waterfront uses. It is a goal of bot the City of. Boston and the commonwealth to encourage this renaissance, to support it tinrougin appropriate public investments, and, most important. $\therefore$ to assure that new development on the waterfront serves the public anc respects those public rights of access and use so important to the sutu of Boston Harbor. 
Digitized by the Internet Archive

in 2011 with funding from

Boston Public Library

http://www.archive.org/details/certificateofsec85mass 
EOEA \#426/4584

Fan Pier/Pier 4

Although the goal of encouraging the Boston Harbor renaissance is an accepted one, the goal of MEPA and the Secretary is to assure that development takes place within an appropriate context. Traditionally, MEPA examines context in terms of environmental impacts and mitigation; section 61 of $\mathrm{ME}$ requires agencies granting permits and licenses to do so only il convinced that the impacts are in fact mitigated. But since the revision of chapter 91 of the General Laws, MEPA's role has beer expanded as the tidelands permit issued by DEQE requires examination of public purpose, public benefit versus detniment, and consistency with the Massachusetts Coastal Zone Management plan. Therefore, it is appropriate for MEPA review of projects requiring chapter 91 licenses to include discussion of fit with the community; of the uses to which a project will be put;- of $t$ : impact of a project on future uses of the harbor: of the ertent of public amenities which will compensate the commonwealth for relinquishing public rights in tidelands, including visual access, parks, and public access; and of the impacts of the project on future developments.

Before me now is one of the most important new waterfront projects in the recent history of the City. Fan Pier and Pier 4 were a part of the original industrial, water transport, and ra transport use mix that dominated the north shore of soutin Bostor for over a hundred years. To the west, across fort point Channel, is the Financial District, with dense commercial development, excellent transit access, high rise construction, and high levels of pedestrian activity. To the south is the Fo: Point Channel District, now being converted to offices, residential uses, museums, an artists' colony, and open space. To the east is Commonwealth.Pier, the Fish Pier, and the Boston Marine Industrial Park, with low structures, incustrial uses, 2 : heavy reliance on truck access for the movement of goods. Furth to the south and east is residential south Boston, a vibrant mi: of residential, local commercial, and open space uses. It is $a$. this nexus and in this changing environment that the Fan Pier/Pier 4 development proposes to locate.

The Fan Pier/Pier 4 project represents a major expansion 0 Financial District uses across the Fort Point Channel into Sout Boston. It will serve as nucleus and stimulant for other major developments, sucin as the world Trade center and the Cabot, Cab \& Forbes site, and will determine the character and use of this part of the City into the twenty first century. The tasi befor 

EOEA \#4426/4584

Ean Pier/Pier 4

the developers, begun in the Draft EIR, is to propose a concept for this use and to explore the significance of this change for the urban environment. The task of the many reviewing bodies, begun during the preparation of the Draft EIR and continuing, is to assure that the final project meets, as far as possible, the many goals and satisfies, as well as possible, the many needs inherent in this special location. The following paragrapis detail the review of the Draft EIR, the concerns that have been. raised by that review, and a process for the resolution of those concerns.

\section{THE DRAFT ENVIRONMENTAL IMPACT REPORT}

The Draft EIR prepared for this project goes well beyond both the breadth of coverage and the depth of detail that is customary in EIRs. By presenting a complete coverage of all planned and potential development in this part: of the soutin End, it provides a truly useful planning document to guide those decisions that must be made by the proponents and public decisic makers in the coming months. By developing a iesser scaie alternative that responds to some of the goals expressed in ear: review, it evidences the proponents' commitment to a project the both meets their legitimate business aims and respects the public's legitimate rights in the waterfront. By proposing several creative and thoughtful mitigation measures, it sets the stage for a successful private/public partnership to provice those transportation and infrastructure improvements necessary support this and other proposed developments in South Boston while limiting the negative effects on the South Boston residential community and the remainder of Boston. The proponents and their consultants are to be commended for the Draft EIR and for their support of informed public review in the best spirit of the Massachusetts Environmental Policy Act.

The high quality of the Draft EIR and the high quality of public and agency review of the project are clearly demonstratec in the volume, quality, and usefulness of the comments receivec on the Draft EIR. AII reviewers, and most particularly the Ean Pier/Pier 4.Citizens Advisory Committee and the Executive Offict of Transportation and Construction, have invested time, effort, and thought in their review of the document and in their commen: to me. The comments, in fact, are of such detail that any technical comments by my office would be redundant. Suftice it to say that the proponents face a chalienge in responding to the 
EOEA \#4426/4584

Fan Pier/Pier 4

comments attached, each of which must be dealt with fully in the Einal EIR. The remainder of my comments serve to highlight the concerns expressed in the comments and my review of the Draft EI. and to suggest a process for resolving these concerns and reporting on them in the Final EIR.

\section{THE CONCERNS}

Not surprisingly, the Draft EIR reveals that the proposed projects will seriously overtax the existing transportation and infrastructure systems serving South Boston. The proposed projects, when combined with all other proposed development in the area, will also stress the systems which may be in place by 1995. The Draft EIR also demonstrates that, while much improved as compared to the original proposal, the lesser scale alternative is of nearly the same size (density) and still raise: many of the same urban design questions of visual impact, wind, shadow, and pedestrian access as did the original proposal. These same concerns are expressed in a different manner under th: Tidelands review of chapter 91 as public purpose, public benefit and water related uses. What is needed is further examination $c$ : the project, the development of an alternative at a reduced scal. in terms of size and use mix, a comparison of the demands the alternatives place over time on South Boston support systems, to the capacity of those systems, and a creative private/public solution to the problem of assuring that mitigation measures are in place when needed. Also needed is further discussion of ways the project alternatives might enhance delivery of public amenities, and further examination of project impacts on harbor uses and future development in South Boston.

Transportation

The most acutely felt and extensively discussed impact of the Fan Pier/Pier 4 developments is its effect on the many modes of transportation needed to serve the project. The proposed project will, by itself, cause roadway capacity failures at numerous intersections leading to and in South Boston. Taken with other proposed projects, even the full planned system including the. Third Harbor Tunnel and Depressed Central frtery will not suffice to eliminate all traftic impacts. Public transportation to south Boston is practically noneristent; even the first phase of Fan Pier/Pier 4 will require paratransit link to south station if it is to achieve its goal of $70 \%$ public transit ridership during peak hours. Parking limitations alone, 
EOEA \#4426/4584

Fan Pier/Pier 4

while profoundly affecting transit use, will not overcome the driving habit of potential project occupants. Truck traffic, while not a major impact of this project, may be compromised by congestion of the street system. This congestion may also lead to diversions of commuter traffic deeper into South Boston, increasing impacts in residential areas.

The Draft EIR proposes a substantial set of mitigation measures to cope with vehicular traffic bound for the facility both without and with the Third Harbor Tunnel/seaport Access Road. The Final EIR must provide considerably more assurance of the feasibility, funding, responsibility, and timing of these measures. Where public funding is assumed, as is the case for much of the proposed work, the funding agency should be identified and contacted to confirm the plans for the mitigation and its timing. Where private funding is proposed, the source should be identified and an unequivocal commitment to timely implementation should be made.

Investigation is also needed of potential traffic mitigatio: measures not considered in the Draft EIR. These inciude the South Boston Bypass or transit use along the rail cut, consideration of the Metropolitan District Commission's goal of eliminating commuter traffic from Day Boulevard, the early construction of a true Seaport Access Road linking the Mass Turnpike to Northern Avenue, enforcement to assure the availability of constructed capacity, and system operation changes to limit or eliminate commuter and truck use of A street, $D$ Street, I Street, and other residential streets in south Boston. The South Boston Traffic Study proposed in the Boston Traffic and Parking Department comment, to be partially funded b: the proponent and supported by the Executive office of Transportation and construction, is a sound finst step in assessing these additional mitigation needs and in identifying $a$ full package of venicular access mitigation for the Final EIR. The elements of this package should be documented completely in terms of funding and timing, as is the case with the other measures proposed.

Traffic impacts may also be mitigated by a reduced scale alternative, "which should be seriously considered. As pointed out in the comments by the CAC, the EOTC, and others, both size reductions and use $\mathrm{mix}$ changes should be investigated with the aim of determining the maximum size of development that can be supported by probable traffic movement capacity. Fon both the 

EOEA \#4426/4584

Fan Pier/Pier 4

lesser scale alternative and for a reduced scaie alternative, project phasing should be determined by the anticipated timing o: mitigation measures. A clear schedule relating the demands of this and other projects to anticipated roadway capacity should be provided. Such size, mix and phasing alternatives might also play a positive role in responding to many of the other concerns detailed below.

Transit systems must also be more extensively considered. The MBTA points out that the project will have measurable effects on the Green Line westbound, as well as the Red, Blue, and orange Lines. It also appears that some of the transit capacity calculations may be overly optimistic. The additional available capacity assumed by the proponent should be confirmed with the MBTA. Analyses should also be prepared of impacts on the more remote segments of the system that will be substantially

affected, such as the Green Iine westbound. Where actions by the proponent on the MBTA are proposed to improve capacity, the MBMA should be contacted to confirm the priority assigned to tiose improvements, the probable availability of private on public funds, and the anticipated date of construction.

Additional consideration must also be given to privete or private/public transit or paratransit links between south statior and the project site. While 4,000 feet is a reasonable walk on $\bar{c}$ fine spring day, it will divert few automobile drivers in

February. The provision of rapid, comfortabie, reliable transfe: from South station will be critical to the success of the project and to limiting vehicular traffic. The importance of this element, especially in the short term, cannot be too highly stressed. In this regard, the innovative proposal for a people mover brought forward recently by the proponents of the worla Trade center should be specifically considered. In the long term, public investment might be brought to bear in relocating the Red Iine to serve the area, providing a direct Blue Iine Iiri to the airport, or other capital intensive plans to cevelop public transportation in South Boston. Whether any such long ter. proposals are reasonable expectations in time to be of any service to this project is in great doubt. The MBTA shouid be approached concerning these plans, their priority, funding, and timing, and the results reported in the FEIR.

Finally, as pointed out most eloquently by the office of Coastal Zone Management and the EOTC, further serious consideration of and private commitment to water based 
EOEA \#4426/4584

Fan Pier/Pier 4

transportation must be provided in the FEIR. This consideration should extend to all uses of water transportation as they relate to this project, with particular emphasis on: communter boat access for persons who will work at the development site; access to and from Logan Airport; and movement among key public destinations within the inner harbor. The Final EIR should include the feasibility study referenced in the Draft EIR as weI as any additional analyses that may be appropriate.

It is not my intent in this or any of the following areas 0 : concern that this project bear all of the responsibility for proposing, assessing, funding, or carrying out mitigation efforts. Rather, it is my intent that the proponents here, othe: private developers in South Boston, major landowners, the City 0 : Boston, and the Commonwealth all engage in a dialogue to reach the goal of a sound support system to serve this and other existing and planned development in South Boston. The results 0 : this dialogue must be reported in tine Final EIR. I will suggest in the final section of this discussion, a mechanism that may serve this end without unduly burdening this or any other single project.

\section{Infrastructure}

While perhaps not as dramatic or as noticeable as the effects on transportation, there are also substantial concerns with the ability of water, sewer, storm water, gas, and electrical systems to serve the total level of aevelopment in tho project area. In my role as Chairman of the Board of Directors of the Massachusetts Water Resources Authority, I am particular:! sensitive to the water and sewer implications of a development that will be the equivalent, of adding a small town to the system. The Boston Globe, on January 24, 1986, carried an article reporting electrical supply problems in the South End, an area undergoing less intense development than that proposed for south Boston. Natural gas, while abundant at the moment, has historically been subject to both production and distribution shortages, nationally and locally. For the level of total development proposed for the north shore of South Boston, each 0 : these systems must be carefully evaluated and measures to assure increased capacity must be developed.

The proponents have, through the Draft EIR, provided the demand data and impact assessments to identify the potential shortfalls in each of these areas. What remains is to determine 
the impacts of future development, the needed remedies and, as is the case in transportation, to apportion the responsibility for these remedies equitably among private proponents for this and other Solth Boston projects and between the private sector as a whole and the public sector.

The comments of the Boston Water and Sewer Commission provide the basis for a sound approach to the water and sewerage aspects of this effort. In essence, they ask that some private funding be provided to upgrade parts of the sewer system in a timely fashion. I endorse this approach, which might be funded through an infrastructure pool or by direct private construction of portions of the needed improvements. The Final EIR should explore these measures, document those to be carried out Boston Water and Sewer, commit to those to be carried out by the Fan Pier/Pier 4 proponents, and identify those likely to be the responsibility of otiner major developments in the area.

In addition, the Final EIR should explore both water = conservation and sewage flow reduction. The water supply of the MWRA is a fired resource for the foreseeable future. It is only by conservation that the system will be able to meet the demands to be placed on it over the next two decades. The Final EIR should determine water conservation measures achievable, on site or elsewhere, describe measures to set off the new demands of tine project, and make commitments accordingly. In terms of sewage capacity, the existing and proposed MWRA sewage treatment plar." are also a fixed resource. The proponent should explore, w:Boston Water and Sewer, measures that both might take to rec infiltration and inflow to reduce the total burden of peak f-ow to the treatment plants. This examination may also include contact with the MWRA to identify non-Boston I/I recuction possibilities, but I expect that sufficient I/I can be found and removed in Boston to meet the 2 for 1 policy that is now erpectec of suburban communities. This should be the goal of tis effort, which should be reported on, the Final EIR.

Storm water management, as pointed out by the Metropolitan Area Planning Council, also requires some additional attention in the Final EIR. Conceptual storm water management plans should be presented in the Final EIR, along with a ciscussion of and commitment to measures to limit the potential effects of storm water discharge on Boston Harbor.

One neighbor to the site, Cabot, Cabot \& Forbes, has 
suggested in their comments the idea of incorporating an underground utility tunnel in New Northern Avenue. This concept should be investigated with the major utility suppliers, including Boston Gas and Boston Edison, to determine its feasibility. Such a concept might allow for the provision of ner service to the site and other sites which will apparentiy be needed to meet the demanas of the proposed project ard other projects. It is also an ideal candidate for private funding by this and other developers in the area.

\section{Tidelands/Chapter 91}

The Draft EIR provides a discussion of the metiods proposed by the proponent to meet the standards of chapter 91. As pointec out by the Division of Wetlands and Waterways, the major concern. under chapter 91 are public purpose, public benefit versus detriment, and consistency with the policies of the coastal zone management program. Several related issues were brought forward as urban design concerns by many of the commenters on the Draft EIR. These included visual effects, wind and shadow effects, anc provisions for public pedestrian access.

The rotion of public purpose is taken in the Draft EIR to mean public access to and use of the waterfront. The Executive office of Communities and Development raises the important question of occupancy by a spectrum of the public as a criterion The Final EIR should speak to this point clearly and consicier a broader range of income levels for residents, as it has agreed tc do for local smali businesses.

Public benefit, as interpreted under chapter 91, includes the provision of ample water related facilities, public use cf those facilities, and public access to those facilities. In this regard, the Office of Coastal Zone Management has suggested a more intensive use of the bulkhead for docking, more explicit connection to the Harbor Walk, increased emphasis on water transportation, and the provision of more transient slips for water access to the site. The Fan Pier/Pier \& Citizens Advisory Committee has raised the question of more general public benefits, such as local job commitments, use of linkage funds to support affordable housing, and other off site benefits of the project. The Final EIR snould explore the suggestions mace by the reviewers for increased public benefit, direct and indirect, and for increases in water dependent uses. In this analysis, explicit consideration should be given to the role of the canal 
EOEA $\# 4426 / 4584$

Fan Pier/Pier 4

and underground parking in providing public amenities and the positive and negative effects of these elements on the master plan.

The Final EIR should eyamine each of the policies of the Coastal Zone Management Program, as articulated in the CZM regulations, and demonstrate how and to what degree each is satisfied by the project and its alternative. The Harbor Park Advisory Committee should also be consulted in this regard.

In terms of visual effects, concerns were expressed with the canyonization of New Northern Avenue, relationship to development proposals for nearby parcels, visual conditions along the proposed canal, visual connection between the inland side of the project and the public open spaces at the waters edge, the . propriety of a major tower structure close to the water's edge, and numerous site layout and design questions. The Final EIR should consider the design of the project in light of these comments and propose one or more alternatives in response to them. One of these alternatives should represent a reduction in total project square footage in order to provide greater flexibility in site layout and to reduce the total mass of the project.

Wind and shadow effects were also extensively discussed in comments. The thrust of these concerns was with the wind and shadow effects on the major public open spaces located to the north of the major building masses and the canal and plaza spaces internal to the project. The wind environment on New Northern Avenue will also be of great importance. Wind and shadow effects should be considered in responding to the requirement for a further consideration of alternatives. It should be noted that I did not require wind tunnel testing in the original scope for this stage of the project. That is still the case, since tine wind erosion testing provides sufficient information for master plan decisions. More detailed wind analyses will be appropriate at the design stage and will be reviewed by the BRA and this office after the completion of the Final EIR and the selection of an alternative for design.

Finally, many urban design comments dealt with pubijc access, both physical and visual. With the major public spaces located north of the main building masses, accessed from the east and west, and apparently isolated by grade changes, there is some question as to the level of "invitation" proviaed to members of 

the general public to enter and use these spaces. This concept, important nere and in the considerations of public benefit under chapter 91, should be explored in the Final EIR and every effort should be made to provide visual and pedestrian pathways from downtown Boston and from new Northern Avenue that lead the public to open spaces and encourage their use by non-residents, as weli as project resiaents and visitors. Specific consiaeration should be given to the effects of access on the use and value of public open space and water dependent uses.

\section{THE FINAL EIR: A PROCESS FOR RESOLUTION}

The Fan Pier/Pier 4 project represents a unique opportunity both for the developers and for the public. While many concerns have been raised by the project as presented in the Draft EIR, virtually all reviewers have expressed a conviction that a successful final project can result from the process now under way. It is important that the spirit of cooperation fostered by the project proponent not be aliowed to fade in the coming months. To that end, I propose three stages of review over the coming months.

First, I suggest that the Fan Pier/Pier 4 Citizens Advisory Committee remain a focus for ongoing public review of the developing master plan and refinements considered for the Firal EIR. To this end, I ask that the MEPA unit be apprised of meetings of the CAC and receive minutes of those meetings. The proponent has agreed to continue meeting with the CAC over the coming months and to fund secretarial and mailing costs for the CAC. My office will attend CAC meetings at critical project junctures and actively seek the input of the CAC in the review of preliminary data and of the Final EIR. In this fashion, the excellent work carried out by the CAC to date can continue to guide and inform the proponents' consideration and the agency review of the project

Second, I propose that a Review Committee of appropriate public and private actors be established to review mitigation plans as they are developed. This group should include representatives of all public agencies with a role in carrying out mitigation actions, private utilities that will ultimate serve the project, and the proponents for other projects in the area. The EOTC has offered considerable assistance in transportation matters. I invite the active participation of the BRA in this process. MY office stands ready to assist in 

convening this group and moderating its discussions. In order for these discussions to be most meaningful, I ask that the Fan Pier/Pier 4 proponents, early in their considerations for the Final EIR, develop a tentative listing of proposed mitigation measures and a preliminary assignment of responsibility for thost measures to public agencies, private entities, and public/privat partnerships. These may then be discussed with all concerned parties prior to the expenditure of major efforts for anaiyses. In this fashion, only the feasible measures need be subject to rigorous analysis. In addition, the agency/proponent review forum will provide a clearinghouse for funding and timing information that will be essential to the Final EIR.

The logical third stage is the Final EIR. It will serve to document the progress made by the proponent, the responses to the concerns raised above and in the comments, the resuits of the ongoing public review by the CAC, and the multidimensional mitigation planning and commitments achieved in the agency/proponent forum. It will be the result of a process extending over the next several months and will provide an opportunity for broad public review of the results of these efforts and, it is hoped, will lead to closure, on the outstancins issues.

January 30,1986 DATE

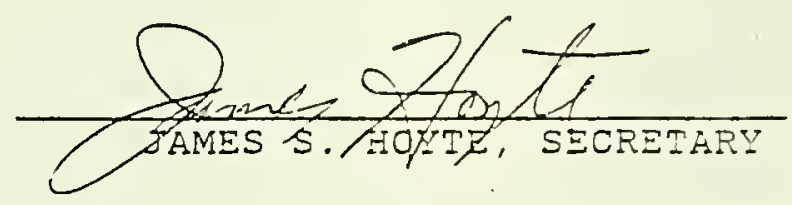

$\mathrm{JSH} / \mathrm{SD} / \mathrm{bk}$ 
